\title{
Understanding Fibre-Matrix Degradation of FRP Composites for Advanced Civil Engineering Applications: An Overview
}

\author{
R. K. Singh Raman ${ }^{1,2, * \mathbb{C}}$, Faye Guo ${ }^{2}$, Saad Al-Saadi ${ }^{2}$, Xiao-Ling Zhao ${ }^{3}$ and Rhys Jones ${ }^{1}$ \\ 1 Department of Mechanical and Aerospace Engineering, Monash University, Clayton, VIC 3800, Australia; \\ rhys.jones@monash.edu \\ 2 Department of Chemical Engineering, Monash University, Clayton, VIC 3800, Australia; \\ faye.guo16@gmail.com (F.G.); saad.al-saadi@monash.edu (S.A.-S.) \\ 3 Department of Civil Engineering, Monash University, Clayton, VIC 3800, Australia; \\ zhao.xiao.ling@monash.edu \\ * Correspondence: Raman.Singh@monash.edu
}

Received: 16 May 2018; Accepted: 13 June 2018; Published: 27 June 2018

\begin{abstract}
Common concretes use considerable amounts of fresh water and river sand, and their excessive use is already seriously implicating the environment. In this respect, seawater and sea sand concrete (SWSSC) is a very attractive alternative, since it addresses the increasing shortage of fresh water and dredging of river sand. A major concern with reinforced SWSSC is the severe corrosion of the steel reinforcements by seawater (that has a very high content of chloride which is very corrosive), thereby seriously impairing the strength of such concrete. Fibre reinforced polymer (FRP) can be a suitable alternative to replace steels as reinforcement. However, there has been little systematic work to understand the degradation kinetics and mechanisms of FRP in the chloride-containing alkaline SWSSC environment. This review first provides an overview of the degradation of FRP composites in normal concrete and chloride-containing alkaline SWSSC environments, and then presents an example of a recent study using scanning electron microscopy (SEM) and Fourier transform infrared spectroscopy (FTIR) that may provide a pathway to systematic experimental approach to understanding such degradation. The review also makes a comprehensive assessment of the influence of environment-assisted degradation on mechanical properties of FRPs.
\end{abstract}

Keywords: seawater and sea sand concrete (SWSSC); durability; carbon fibre reinforced polymer (CFRP); glass fibre reinforced polymer (GFRP); basalt fibre reinforced polymer (BFRP)

\section{Introduction}

Global population is expected to increase to $>9$ billion by 2050 [1]. As a result, the demand for infrastructure and construction materials such as concrete is set to increase steeply from the current annual usage of $5 b \operatorname{yard}^{3}$ [2], which will cause shortage of fresh water and river sand (i.e., the two main ingredients of conventional concrete). Currently, billions of litres of fresh water are used in the mixing, curing and cleaning stages of concrete production [3]. On the other hand, use of large quantities of river sand causes sand-dredging and damages ecosystem (fish-depletion, floods, erosion, landslides) [4]. In fact, in some areas this is already being addressed, as is evident from the article, "Mumbai Government Bans River Sand Mining" [5]. The demand of fresh water and river sand will be further accentuated by the increasing need of additional coastal infrastructures due to the rising sea level [6], which will require transport of large quantities of river sand and fresh water from inland to the coastal areas. Therefore, there is a great value in finding substitutes for the fresh water and river 
sand in production of conventional concrete. The potential use of seawater and sea sand concrete (SWSSC) is a hugely attractive proposition.

SWSSC is a hugely attractive alternative to traditional concrete, but it also comes with an enormous challenge of finding a suitable reinforcement material since it will be nearly impossible to use the traditional reinforcement material, i.e., carbon steels since they will suffer severe corrosion due to very high chloride contents of seawater and sea sand. 'Concrete cancer', which is an enhanced corrosion of steel reinforcement by $\mathrm{Cl}^{-}$ions causing concrete spallation and cracking even in the case of the conventional concrete, will only be highly accelerated in the presence of seawater in SWSSC. Fibre reinforced polymer (FRP) that may suffer very little corrosion in chloride solution/seawater (in comparison to carbon steels) is a highly suitable alternative material for SWSSC reinforcements. FRPs also possess competent mechanical properties to carbon steels. Though both glass-fibre and carbon-fibre reinforced polymers (i.e., GFRPs and CFRPs) are the traditional FRP materials, glass fibres are considerably cheaper (than carbon fibres) and hence GFRPs are most widely used [7], even though carbon fibres possess a far superior strength-to-modulus ratio as well as resistance to environment-assisted degradation [8].

It is important to understand the degradation of FRPs in the alkaline environment of concrete, particularly in the mixed alkali + chloride environment of SWSSC. There is considerable literature on the deterioration in mechanical properties of FRPs after pre-exposure to simulated environment of traditional concrete [7,9-25] as well as a few similar studies after pre-exposure to SWSSC [11,26,27]. There are a few reports also on deterioration in mechanical properties of FRPs under the condition of simultaneous exposure to the simulated environment of SWSSC and applied load [28,29]. However, the chemical aspects of the degradation of the FRPs (and more specifically, the fibre-matrix interface) are poorly understood.

This review first presents a brief overview of the considerable knowledge of the degradation of FRPs in normal concrete environment as well as relatively limited knowledge of the degradation of FRP composites in chloride-containing alkaline SWSSC environment, particularly the influence of environment-assisted degradation of mechanical properties of FRPs under the two conditions. This review also presents the findings of a recent study that, on the basis of microscopic and spectroscopic investigation, suggests the role of seawater in retarding the chemical degradation of certain FRPs in SWSSC, i.e., the beneficial effects of using seawater-FRP combination.

\section{Mechanical Properties of FRPs Pre-Exposed to Traditional Concrete Environments}

Several studies have reported degradation in mechanical properties of bars of different FRPs (viz., glass fibre reinforced polymer (GFRP), carbon fibre reinforced polymer (CFRP), and basalt fibre reinforced polymer (BFRP)) after their pre-exposure to different simulated civil engineering environments, such as the alkaline environment of normal concrete [7,9-25]. These studies identified a few factors that influence the mechanical properties. There are several reports on the degradation of GFRPs such as the factors that influence the degradation, e.g., $\mathrm{pH}$ [16], exposure temperature [18], moisture content of concrete [10,12,14], polymer type [9] and the magnitude of pre-loading [7,13,19], as well as the GFRP degradation mechanism [20-23]. When exposed to distilled water, simulated concrete solution or concrete leachate solution, vinylester resin of GFRP is reported to plasticize [30]. However, degradation of both matrix and fibre was found to be accelerated in the alkaline solution. Similar findings were also reported for epoxy-based BFRP [31], but the reports on degradation of BFRPs are limited $[11,15,24,25]$. Wu et al. [11,25] found the retained tensile strength of BFRP bars to reduce much quicker in the simulated alkaline pore solution than in deionized water, salt, or acid environment. Serbescu et al. [24] suggested the exposure time to be the most important factor affecting the degradation of BFRPs. Benmokrane et al. [15] investigated the effect of polymer type on degradation of BFRP bars and found a basalt/vinyl ester FRP to have to an inferior resistance to the basalt/epoxy FRP in an alkaline solution. 


\section{Mechanical Properties of FRPs Pre-Exposed to SWSSC}

With the huge potential of SWSSC, it is mandatory to understand the durability of the strengthening rebars of FRPs in the relatively new environment of SWSSC. There are reports comparing the degradation in mechanical properties of FRPs in normal concrete or seawater alone. While the highly alkaline concrete environment is reported to be highly detrimental, seawater alone is reported to have only a marginal effect $[10,11,31-33]$. Chen et al. [10] found GFRPs to retain $74 \%$ of its tensile strength after exposure to seawater, $71 \%$ after exposure to distilled water and only $64 \%$ after exposure to alkali solution (exposure in each case was for 70 days at $60^{\circ} \mathrm{C}$ ). Whereas, strength retention of CFRP was $96 \%$ after exposure to the alkali solution. Wu et al. [31] reported respectively similar strength retention for GFRP, BFRP, and CFRP after 60 day immersion in alkali, seawater, and distilled water.

The preceding description concerns the degradation of FRPs in single environment of alkali, seawater, or distilled water, whereas SWSSC constitutes a mixed environment of alkali + high chloride content of seawater. Very little is reported on the degradation in mechanical properties of FRPs after pre-exposure to the simulated environment of SWSSC [9-11,16,32-35]. In a study by El-Hassan et al. [36], the degradation mechanism of GFRP during exposure to seawater-containing concrete for 15 months included hydrolysis of polymer matrix and loss of strength of the fibre-matrix interface, but the fibre itself was not found to have suffered much attack. As shown in Figure 1a,b, Wang et al. [26] have recently carried out a comprehensive study on the retention in tensile strength of BFRPs and GFRPs after exposure to simulated SWSSC solutions of normal $(\mathrm{N})$ and high performance (HP) concrete at different temperatures $\left(32,40\right.$, and $\left.55{ }^{\circ} \mathrm{C}\right)$. The normal concrete $(\mathrm{N})$ has much greater alkalinity than the high performance concrete (HP), as also suggested in this article. It is evident from Figure 1a,b that the tensile strength retention of both BFRP and GFRP decreased with the increase in temperature, duration of exposure, or the alkalinity of the exposure environment. However, the decrease in tensile strength retention was more rapid for BFRP than for GFRP. The rapider degradation of BFRP is consistent with the greater water uptake and the greater extent of chemical attack of fibre of BFRP (than GFRP), as described in the succeeding section.

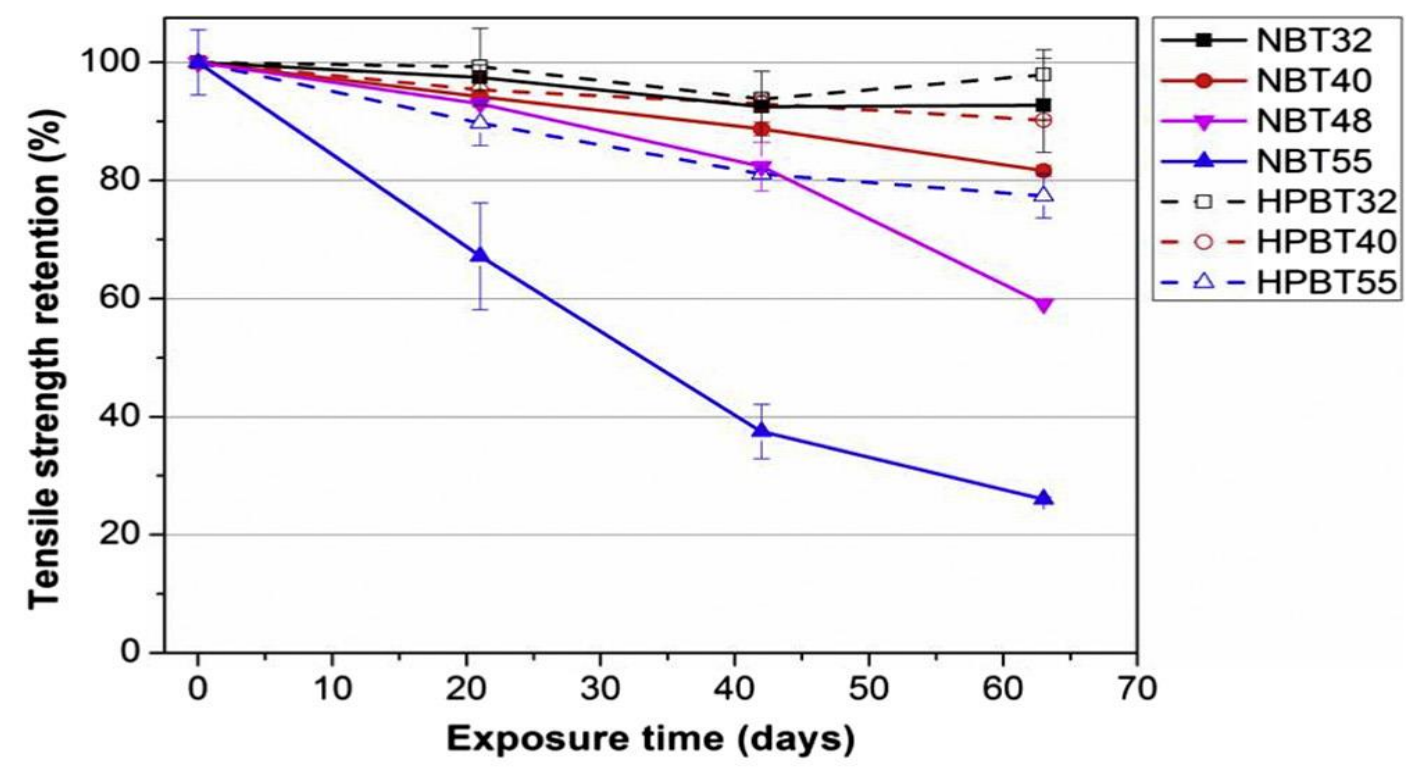

(a)

Figure 1. Cont. 


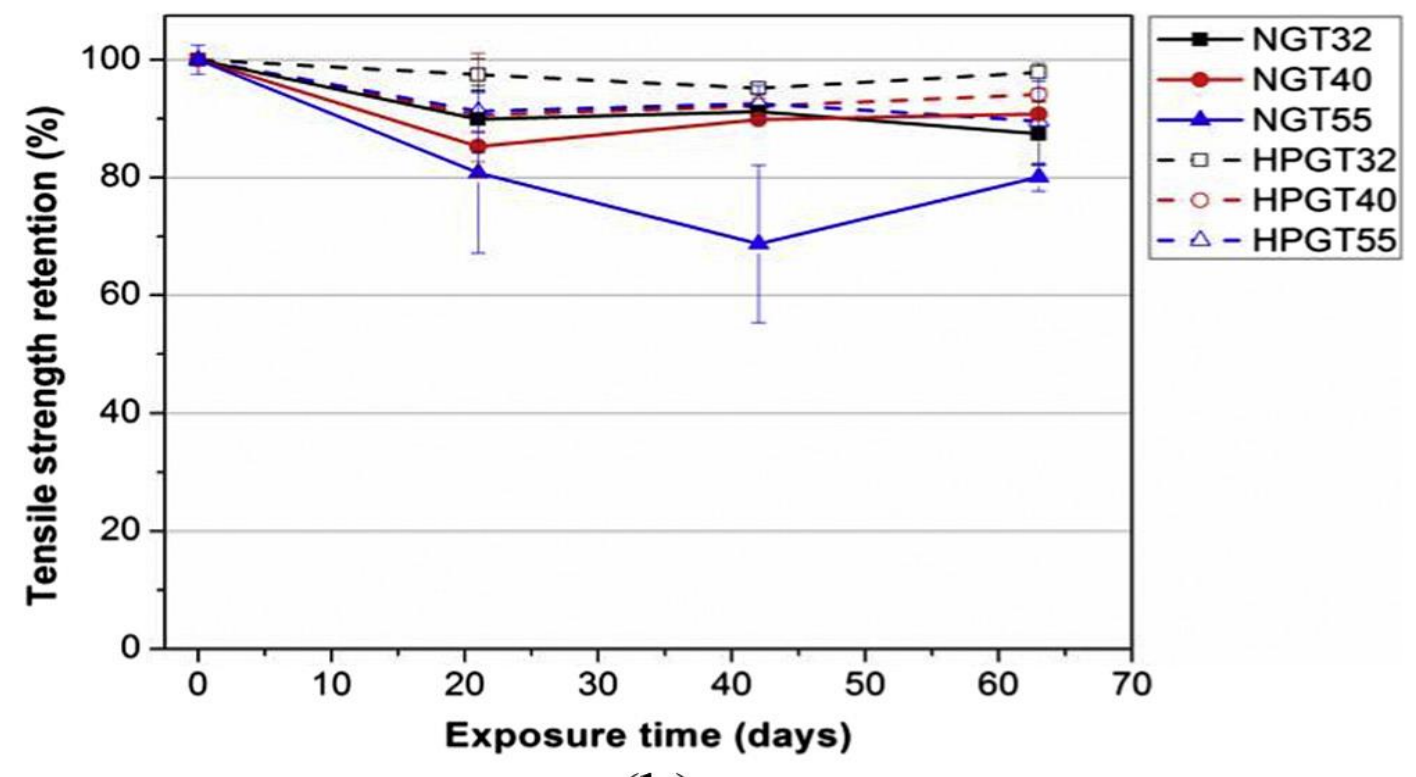

(b)

Figure 1. Tensile strength retention of FRP bars after pre-exposure to the simulated solutions of normal concrete $(\mathrm{N})$ and high performance (HP) for different durations at different temperatures $(32,40$, and $55^{\circ} \mathrm{C}$ ): (a) BFRP and (b) GFRP. (Adapted from [26], with permission from Elsevier, 2018).

Figure 2 compares the trends in the influence of temperature, duration of exposure or the alkalinity reported in Wang et al.'s study [26] with the limited data on degradation of BFRP in another study [11], and the trends are found to be consistent.

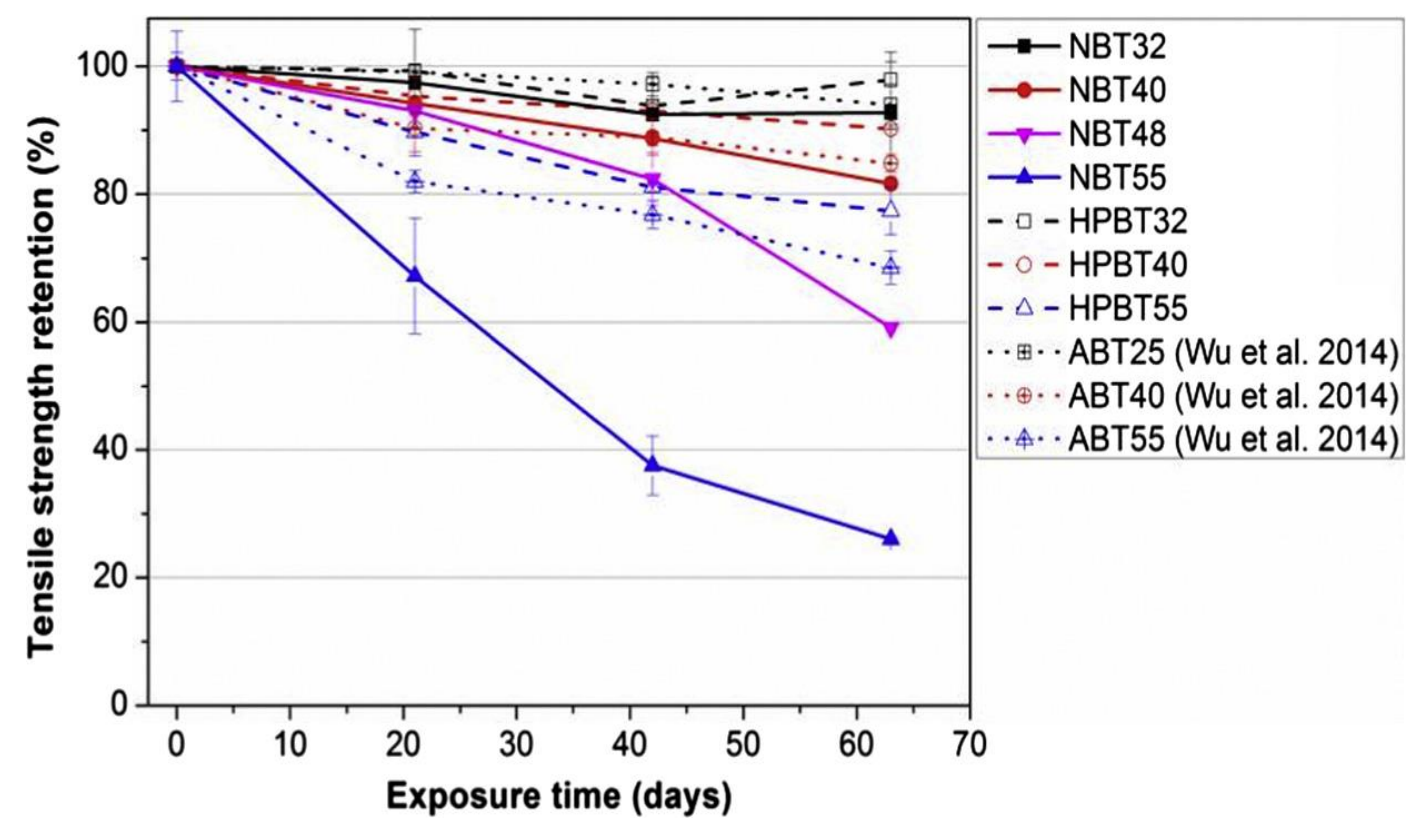

Figure 2. Comparison of tensile strength retention of BFRP bars in SWSSC and alkaline environments at different temperatures (Adapted from [26], with permission from Elsevier, 2018).

In order to understand the role of the extent of the degradation of fibres during pre-exposures on the tensile strength retention, Wang et al. [26] carried out a thorough microscopic investigation of the cross-sections of the BFRP and GFRP after pre-exposure to normal (N) and high performance (HP) concrete solutions at different temperatures $\left(32,40\right.$, and $\left.55^{\circ} \mathrm{C}\right)$ for the longest test duration $(63$ days). 
For comparison, unexposed samples were also examined. Figures 3 and 4 show the scanning electron microscopy (SEM) images of the ground and polished cross-sections.

In the case of the unexposed BFRP, the basalt resin, fibre, and the fibre-resin interface are all largely intact, as seen in Figure 3a. The a few minor cracks seen at the fibre edges were attributed to the grinding and polishing process employed for the specimen preparation. In the case of the pre-exposed $\mathrm{BFRP}$, the fibre and fibre-resin interface in the areas near the edge the bar were the first to come in contact with the aggressive environment and suffer degradation. The attack front gradually progressed towards the centre of the bar specimen with increase in the duration of exposure on the temperature (as shown in Figure 3b-d). Also, the attack can be seen to intensify with the increasing duration or temperature of exposure.

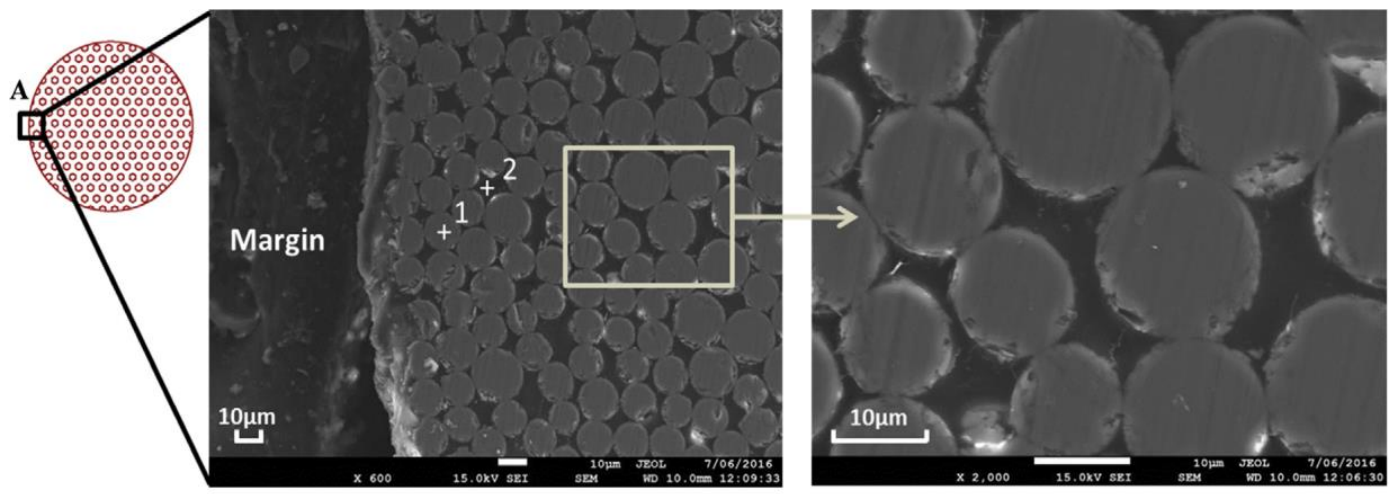

(a)
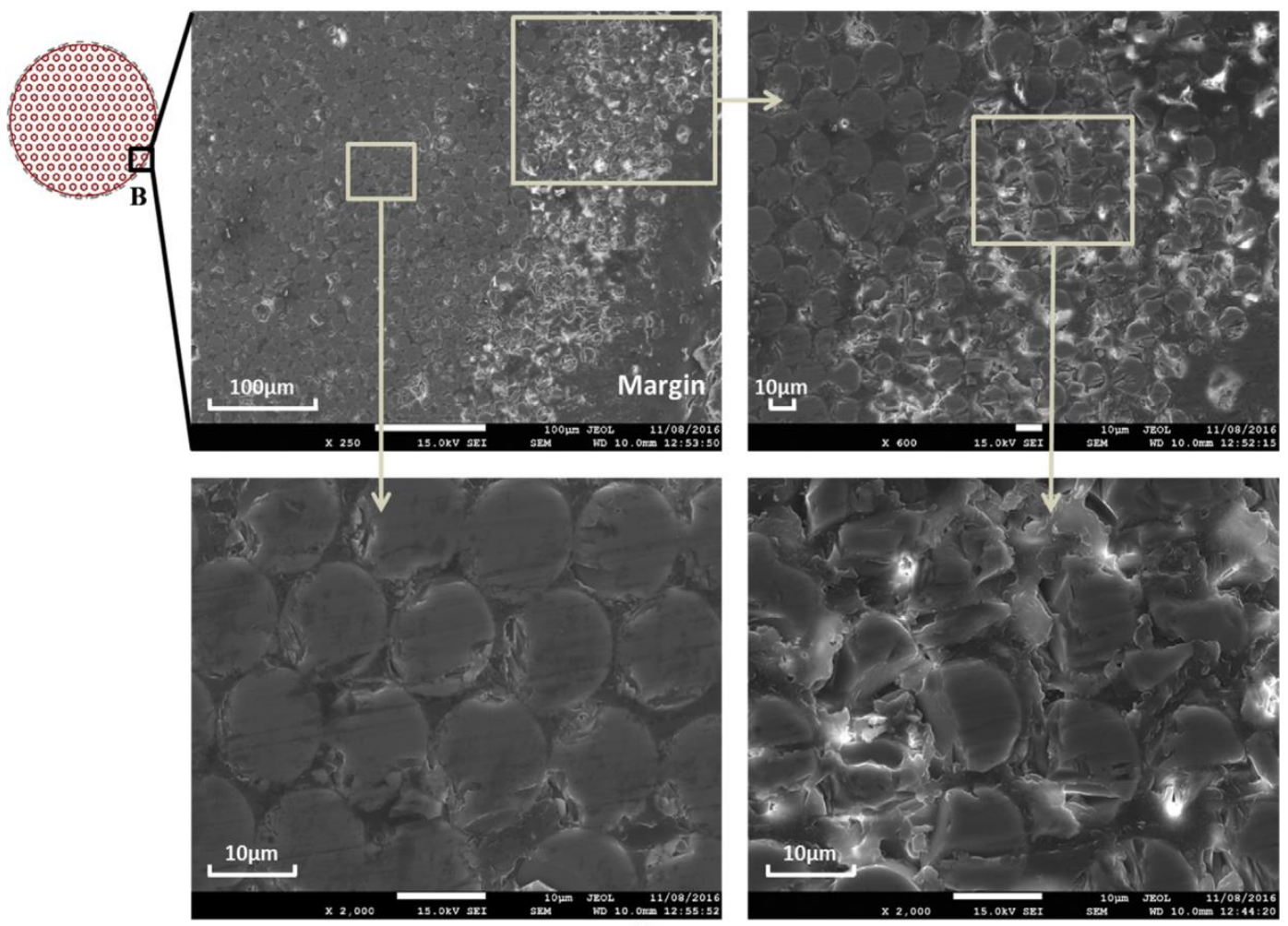

(b)

Figure 3. Cont. 

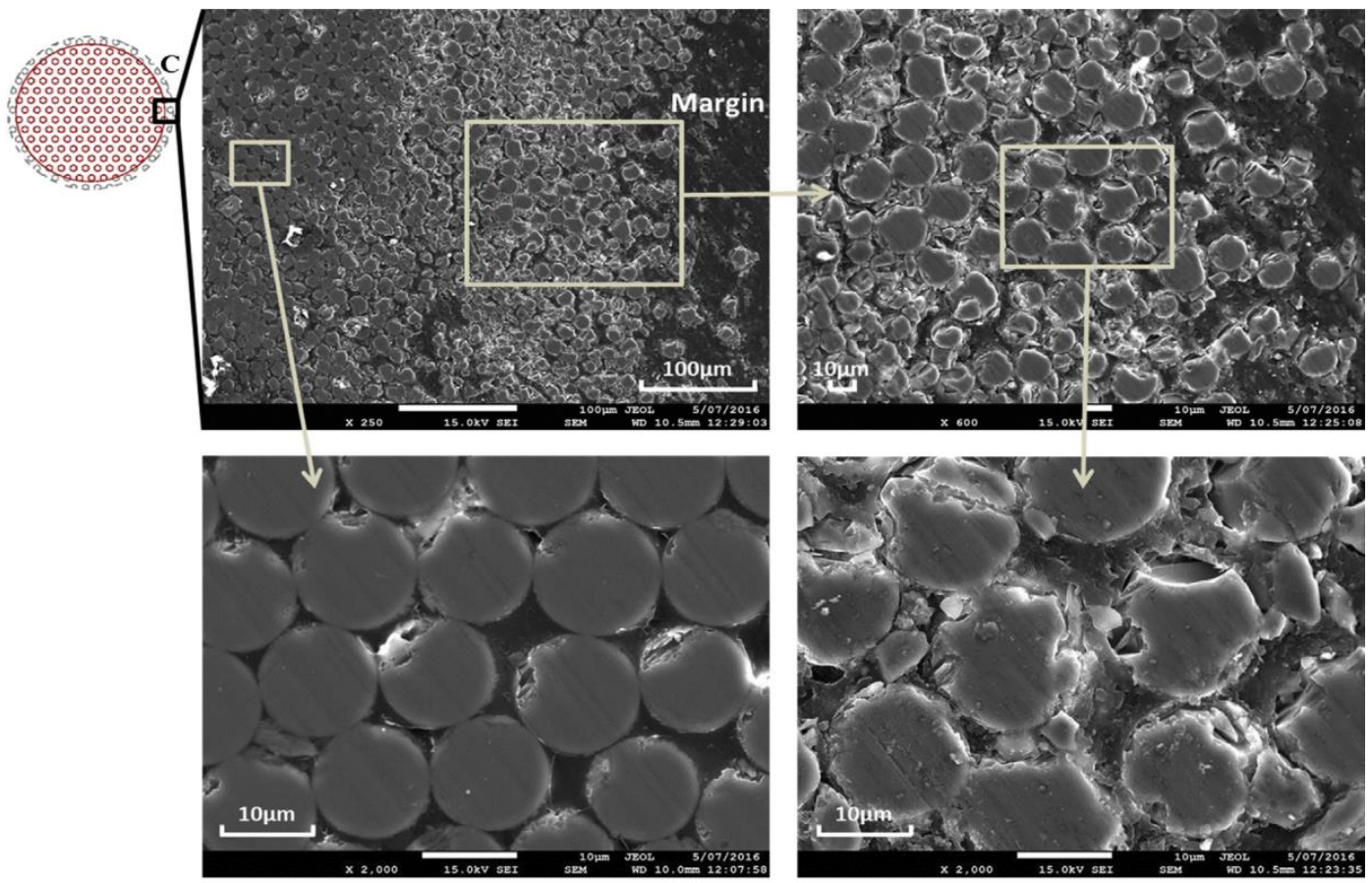

(c)
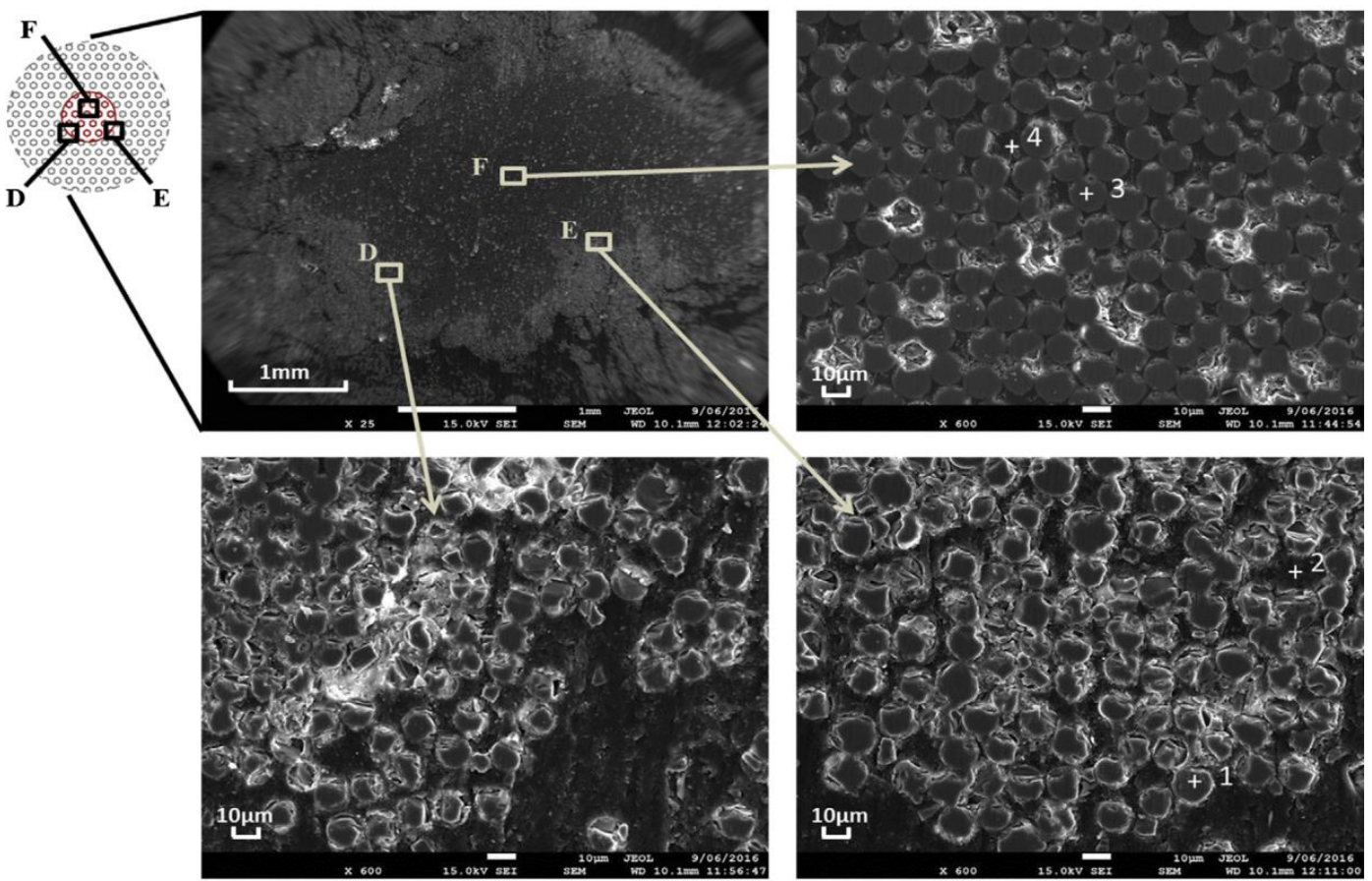

(d)

Figure 3. SEM images of the cross-sections of BFRP: (a) without exposure and (b) after exposure to SWSSC for 63 days at $32^{\circ} \mathrm{C}$ [26]. SEM images of the cross-sections of BFRP after exposure to SWSSC for 63 days at: (c) $40{ }^{\circ} \mathrm{C}$ and (d) $55^{\circ} \mathrm{C}$ (Adapted from [26], with permission from Elsevier, 2018).

The trend described above for BFRP was found to be same for GFRP (Figure 4). However, the extent of attack was relatively less for GFRP, which is consistent with the greater tensile strength retention of GFRP (as seen in Figures 1 and 2). 

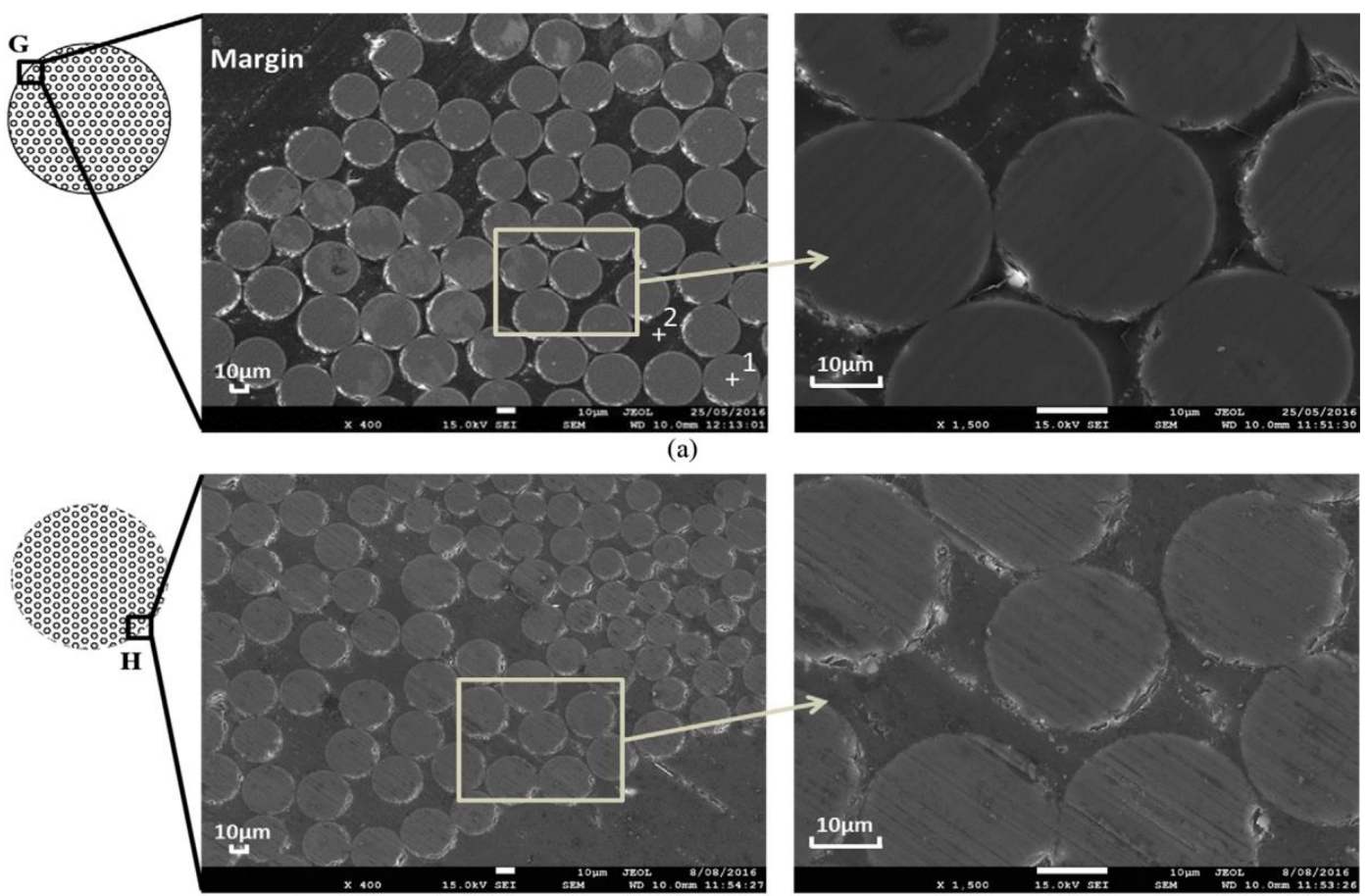

(b)
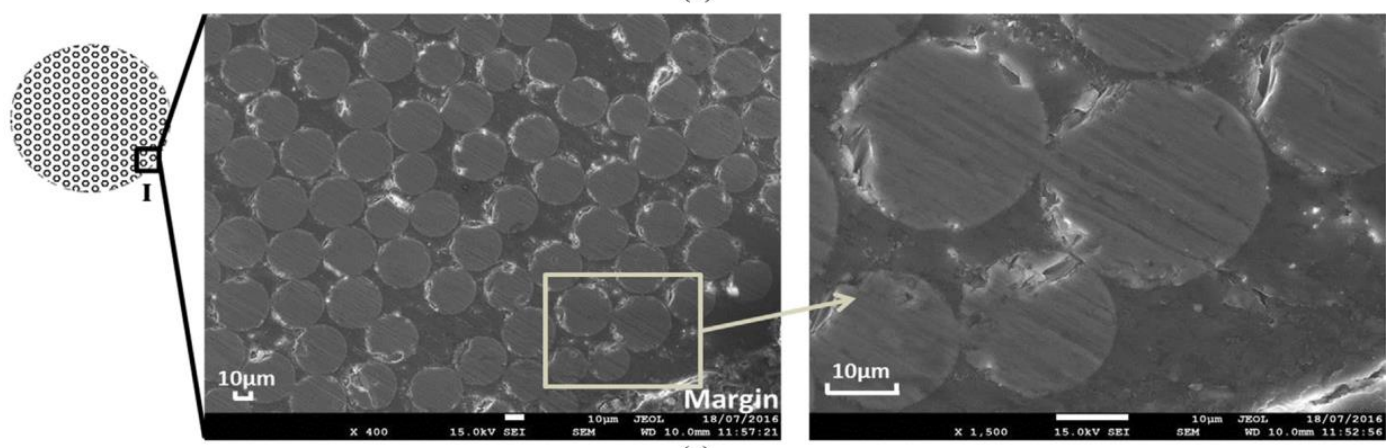

(c)

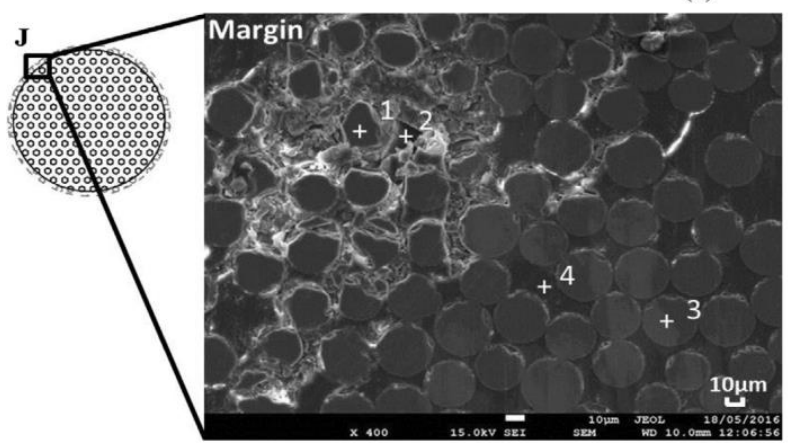

(d)

Figure 4. SEM images of the cross-sections of GFRP: (a) without exposure, and (b-d) after exposure to SWSSC for 63 days respectively at 32, 40, and $55{ }^{\circ} \mathrm{C}$ (Adapted from [26], with permission from Elsevier, 2018).

\section{Moisture Uptake of FRPs and Advanced Characterisation of Degradation of Fibre-Matrix Interface}

Very recently, authors' group has carried out further investigation to characterise the contribution of epoxy matrix to FRP degradation during exposure. In this study, water uptake of FRPs was determined during exposure to different test solutions simulating normal concrete (NC), high performance concrete (HPC), seawater and sea sand normal concrete (SWSSNC), seawater and sea 
sand high performance concrete (SWSSHPC). In addition, the solid residue generated upon evaporation of the remaining test solutions at the end of the six-month exposure to the simulated environments were examined using attenuated total reflectance-Fourier transform infrared spectroscopy (ATR-FTIR) to establish whether the residues contained spectral evidence for epoxy matrix (which will confirm leaching of epoxy during exposure).

Moisture uptakes of different FRPs (CFRP, GFRP, and BFRP) during exposure to different solutions at $60{ }^{\circ} \mathrm{C}$ for up to six months are plotted in Figure $5 \mathrm{a}-\mathrm{c}$ (average weight gains are plotted with the normalised immersion time (i.e., immersion days $1 / 2)$ ).

Moisture uptake (weight gain) of each FRP increased with immersion time, however, the weight gains in DW, HPC, and SWSSHPC (low alkali environments) plateaued after 30 days, whereas the FRPs exposed to NC, SWSSNC (the higher alkalinity environments) continued to gain weight at high rates for the entire test duration of 180 days. The greater moisture uptake in the high alkali environment (NC/SWSSNC) is consistent with the greater loss in tensile strength of FRPs in the two environments, as shown in Figures 1 and $2[10,26]$. In fact, BFRP showed an acceleration in weight gain after $~ 90$ days, which is also consistent with the much accelerated loss in tensile strength of BFRP in high alkali environment (Figure 1a).

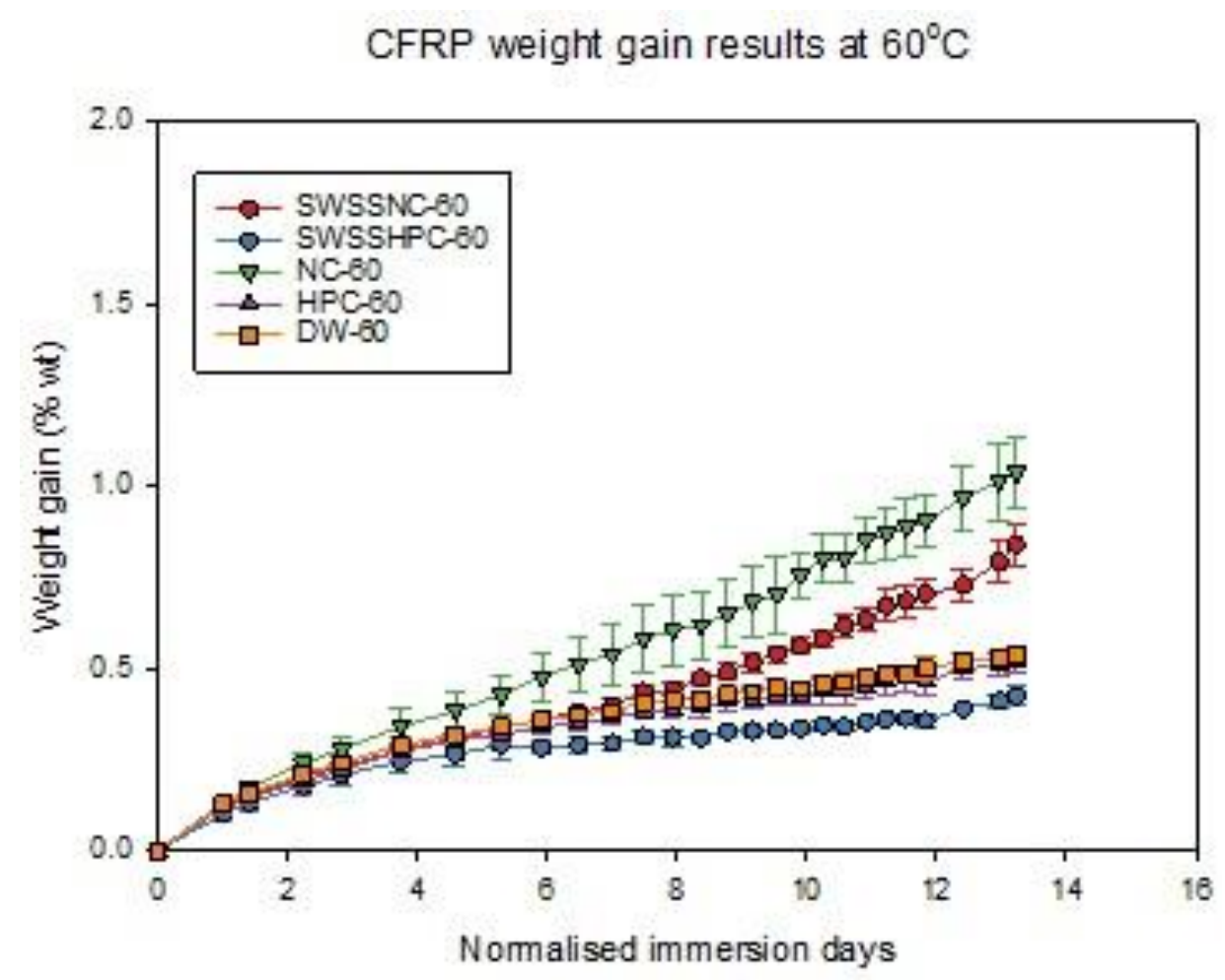

(a)

Figure 5. Cont. 


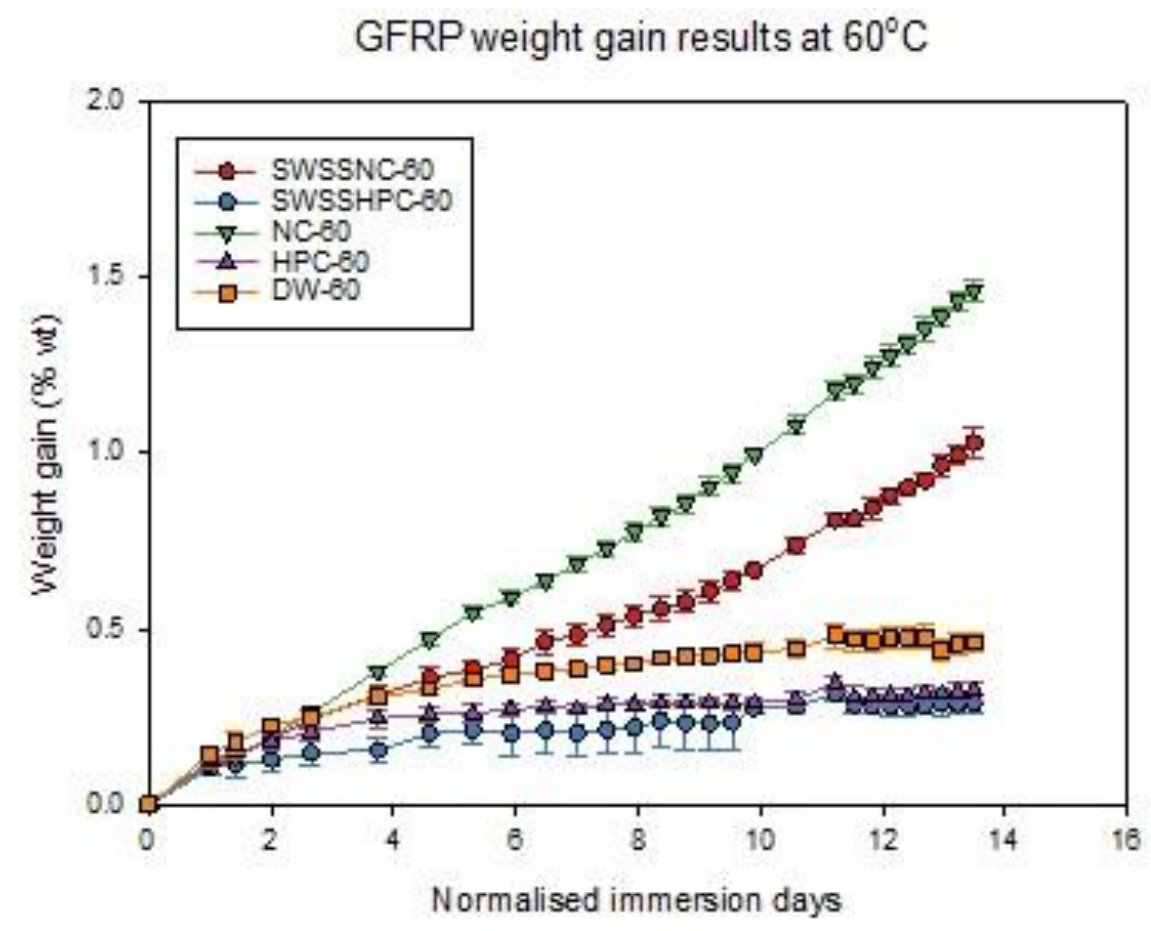

(b)

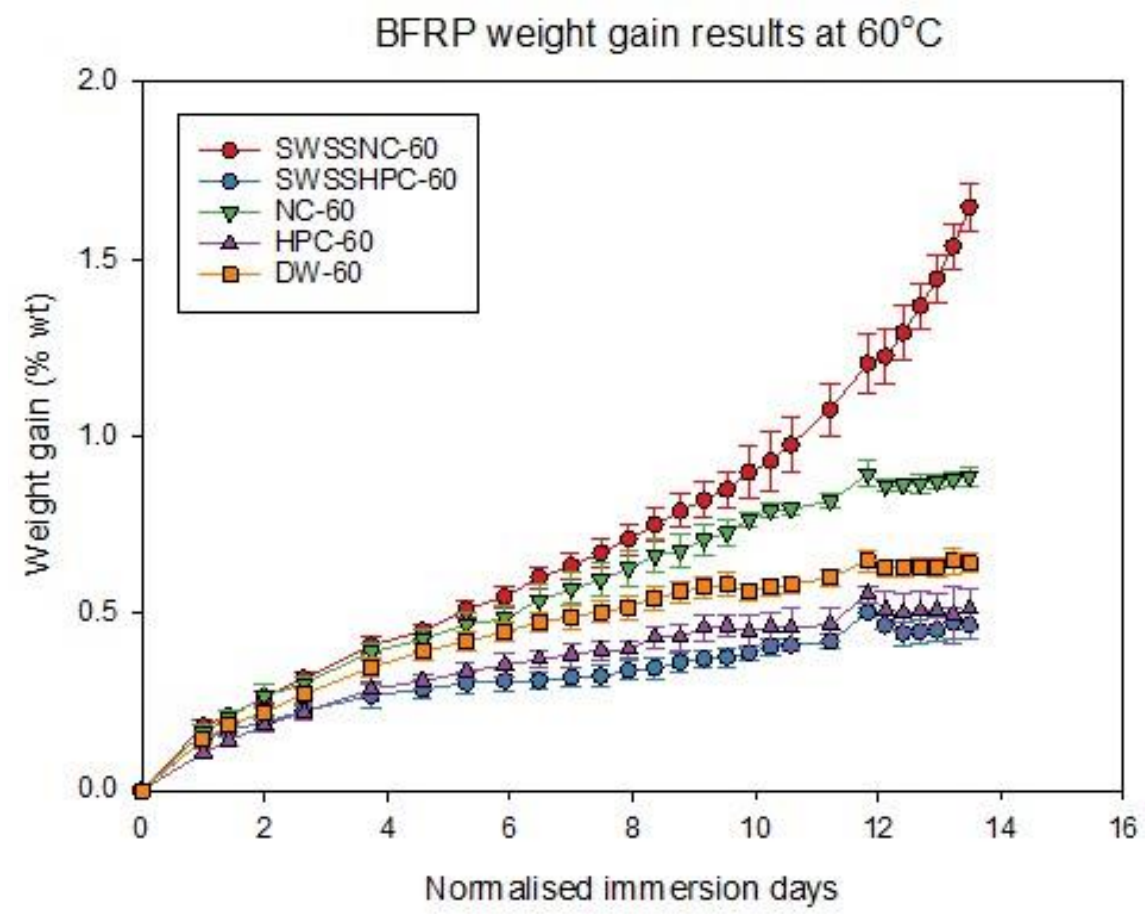

(c)

Figure 5. Moisture uptake of (a) CFRP (b) GFRP (c) BFRP during exposure to different testing solutions at $60^{\circ} \mathrm{C}$ for up to six months (Adapted from [37,38], with permission from Elsevier, 2018).

Moisture uptake by each FRP type was minimum in the low alkali environments (HPC and SWSSHPC), and between the two environments, it is interesting that the moisture uptake was lower when seawater was present (i.e., SWSSHPC $<$ HPC). In fact, even between the two high alkali environments (i.e., NC and SWSSNC), the water uptake was lower when seawater was present (i.e., SWSSNC $<\mathrm{NC}$ ). These observations suggested the beneficial role of the presence of seawater and sea sand in resisting water uptake/degradation. The exception was BFRP that suffered considerably greater 
water uptake in SWSSNC than in NC, particularly after 90 days of exposure, indicating damaging role of sweater in this case.

Figure 6 shows the FTIR absorption spectra of unexposed FRPs (i.e., reference) and the residues of the SWSSC solutions after exposure of FRPs for 84 days at $55^{\circ} \mathrm{C}$ [27]. The bands of the reference spectrum are identified in the literature [39-43]. The bands present in the spectrum for the FRP reference are also present in the spectra for the two residues, confirming the leaching of FRP matrix into the simulated SWSSC solutions during exposure.

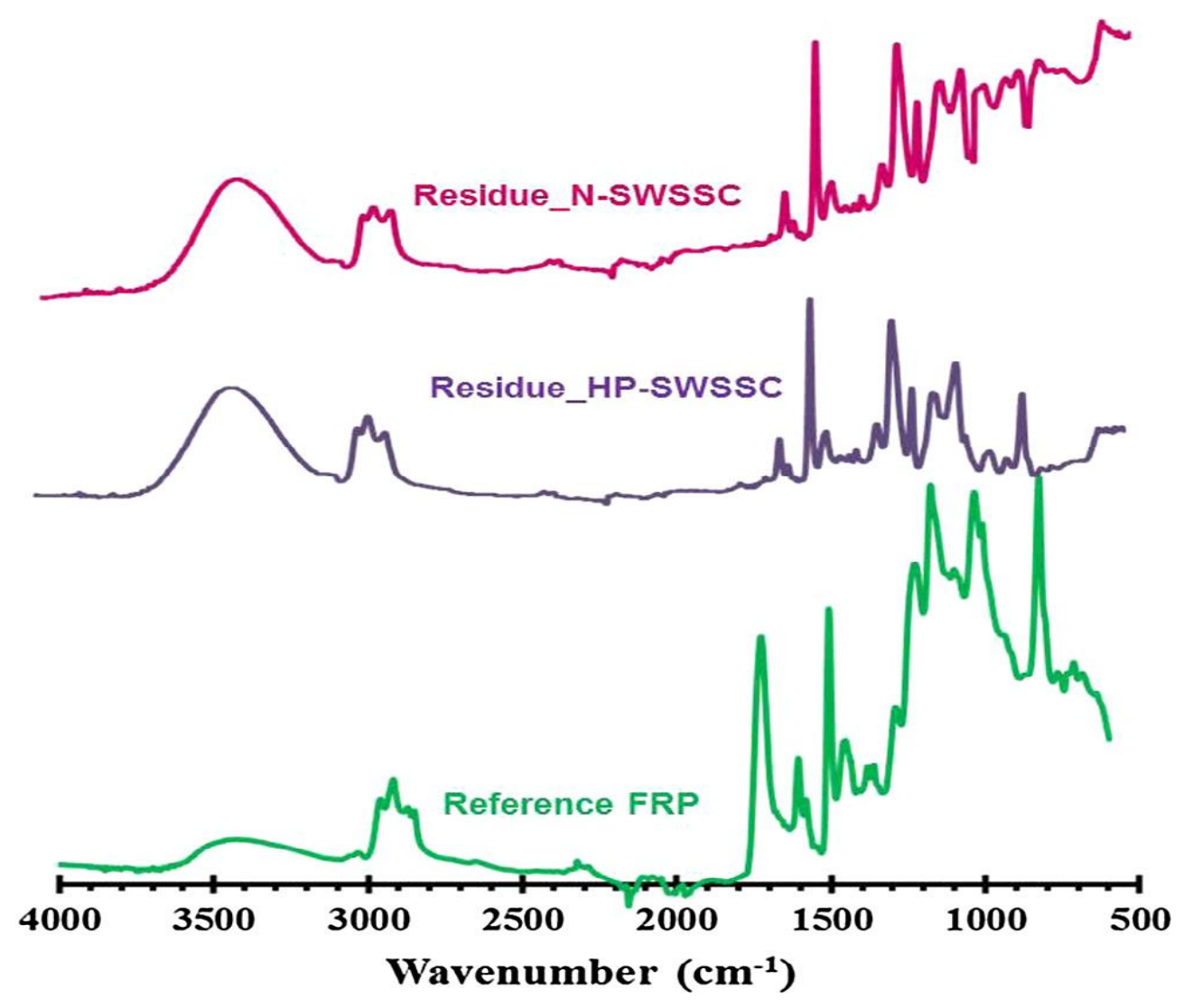

Figure 6. Representative FTIR spectra for FRPs and those for the residues collected after exposure to the simulated normal (NC) and high performance (HP) SWSSC solutions. (Adapted from [27], with permission from Elsevier, 2018).

The SEM images in Figures 3 and 4 provide convincing evidence of degradation of fibre and fibre-epoxy interface due to exposure to SWSSC environment. However, it may not be convincingly concluded whether matrix suffered degradation due exclusively to exposure since it could be argued that the degradation of the fibre-matrix interface seen in Figures 3 and 4 [26] might have been caused (or accentuated) just by the grinding of the samples that is employed for revealing the cross-section of the pre-exposed samples. To address this, the authors also employed an alternative approach for examining the cross-section of the pre-exposed FRP samples, in order to circumvent the likely mechanical damage of the fibre-matrix interface during sample preparation by grinding/polishing. In this alternative approach, the specimens were exposed to liquid nitrogen that embrittled the FRPs and facilitated brittle fracture along fibre-matrix interface under an applied load. The liquid nitrogen fracturing enabled observation of a mechanical damage-free interface by SEM.

As shown in the representative SEM images for BFRP and GFRP immersed in SWSSC at $60^{\circ} \mathrm{C}$ for 180 days (Figure 7), extensive fibre degradation resulted, such as pits, plate-shape corrosion products, ring-shape cracks, and corrosion shells with a porous structure. Such fibre degradation caused the interface debonding that facilitated water penetration/moisture uptake. The study also confirmed the 
extent of degradation to increase with the alkalinity of the environment (i.e., NC, SWSSNC caused greater degradation than HPC, SWSSHPC).
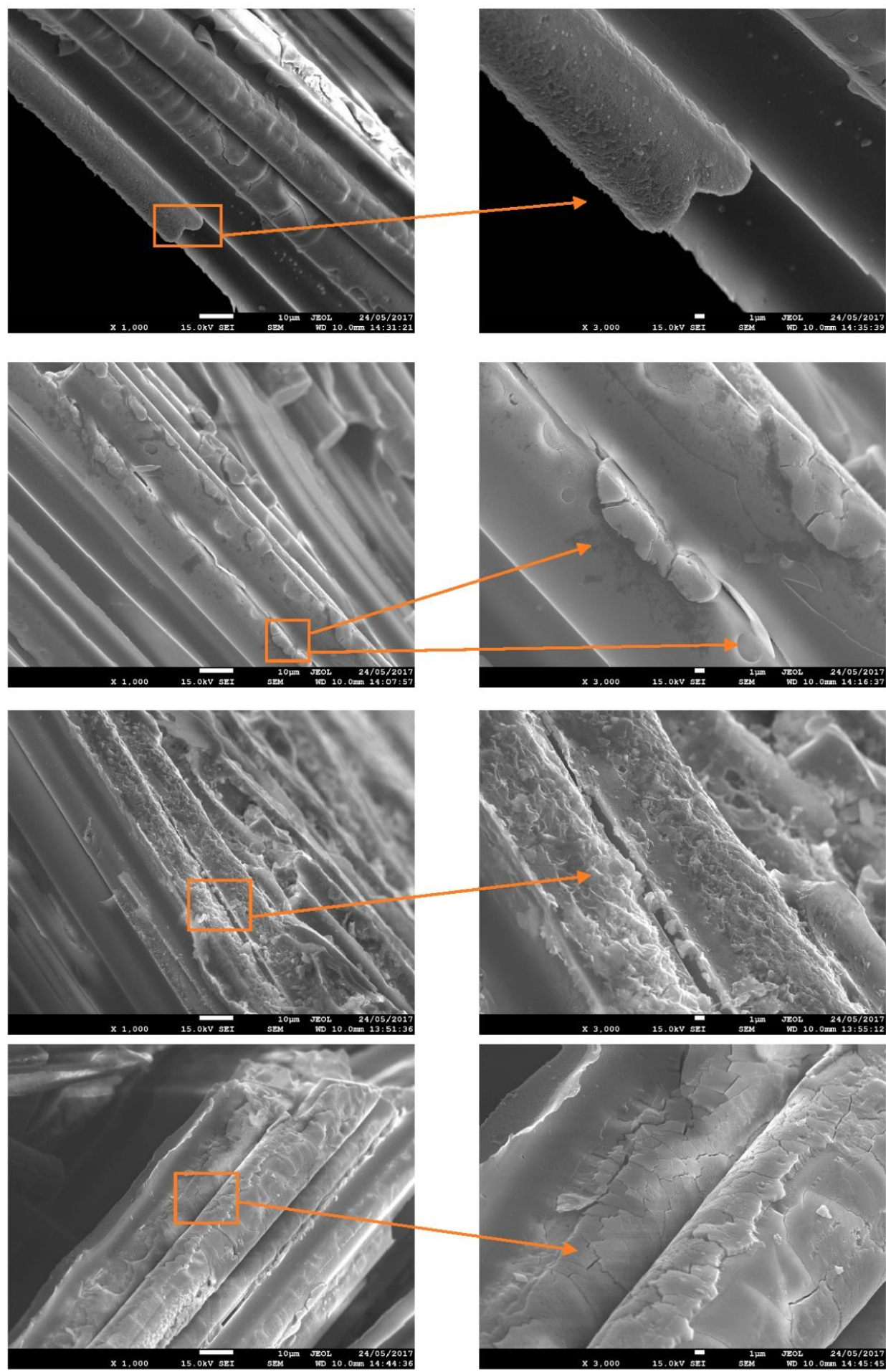

(a)

Figure 7. Cont. 

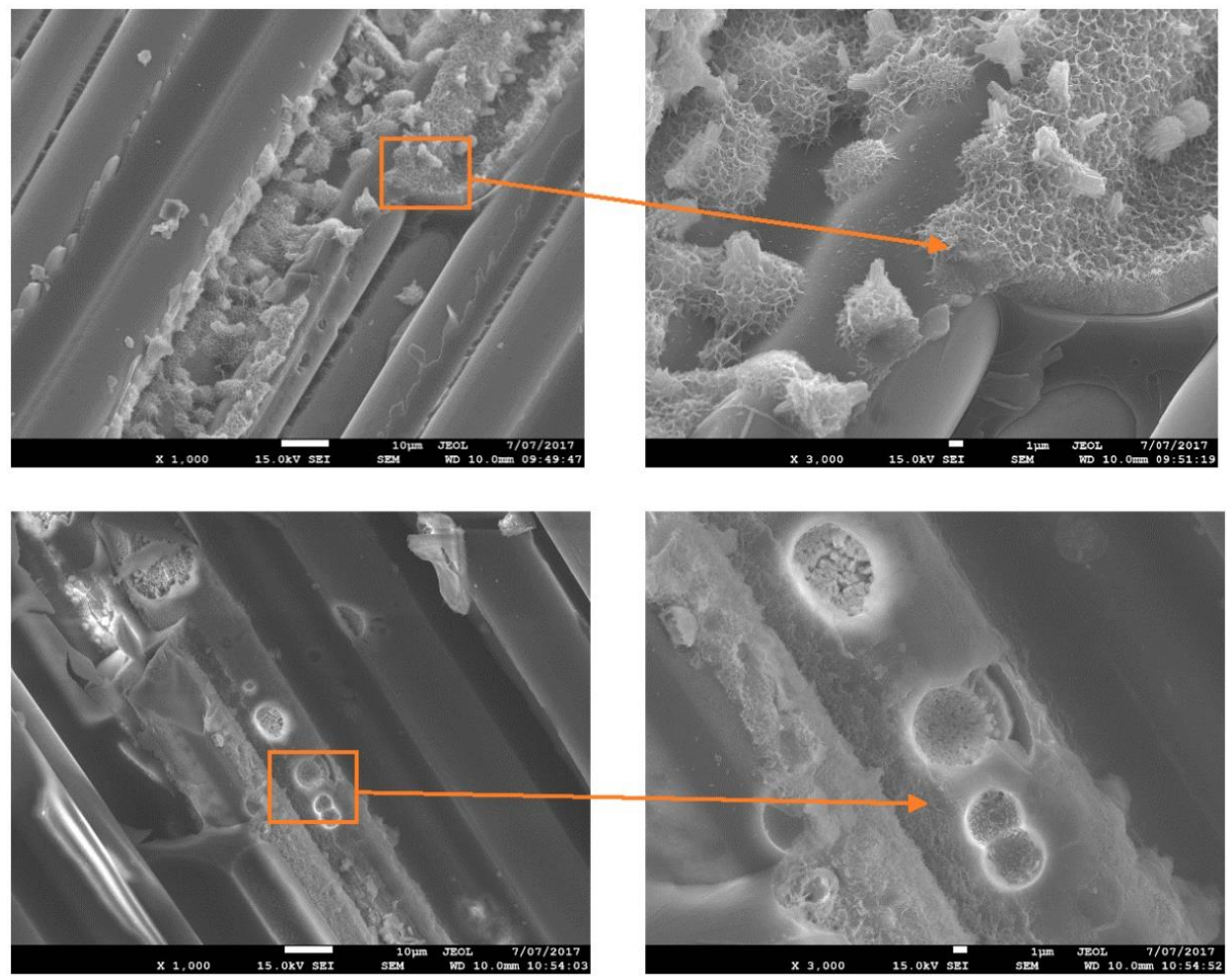

(b)

Figure 7. SEM images of (a) BFRP (b) GFRP exposed to SWSSC at $60{ }^{\circ} \mathrm{C}$ for 180 days (Adapted from [38], with permission from Elsevier, 2018).

Other studies have also reported corrosion shell formation and pitting of glass or basalt fibres due to exposure to alkaline environment, as a result of the reaction of alkali-ions with silicate in fibres (Equation (1)) [44-47]. Further destruction and dissolution of silicate network of fibres progresses following Equation (2) [45-49].

$$
\begin{gathered}
\equiv S i-O R+\left(H^{+}+O H^{-}\right) \rightarrow \equiv S i-O H+R O H \\
\equiv S i-O-S i \equiv+\left(R^{+}+O H^{-}\right) \rightarrow \equiv S i-O H+R O-S i
\end{gathered}
$$

In contrast to their extensive degradation in SWSSC (Figure 7), fibres in BFRP and GFRP suffered insignificant degradation in distilled water at $60{ }^{\circ} \mathrm{C}$ (Figure 8).

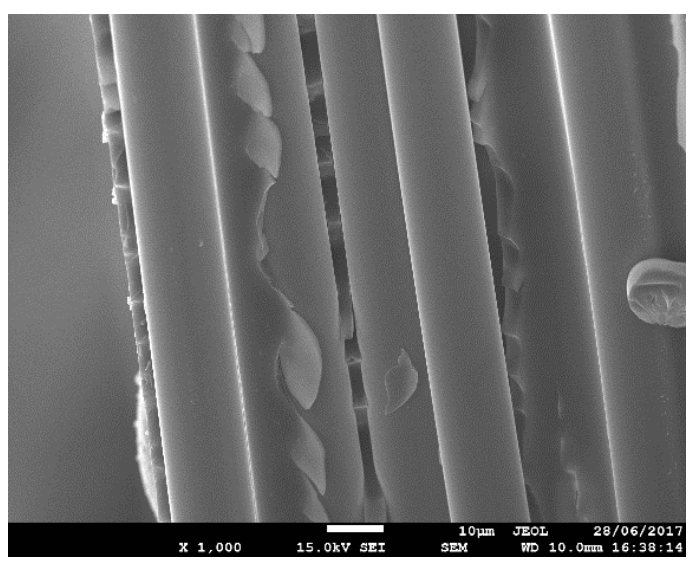

(a)

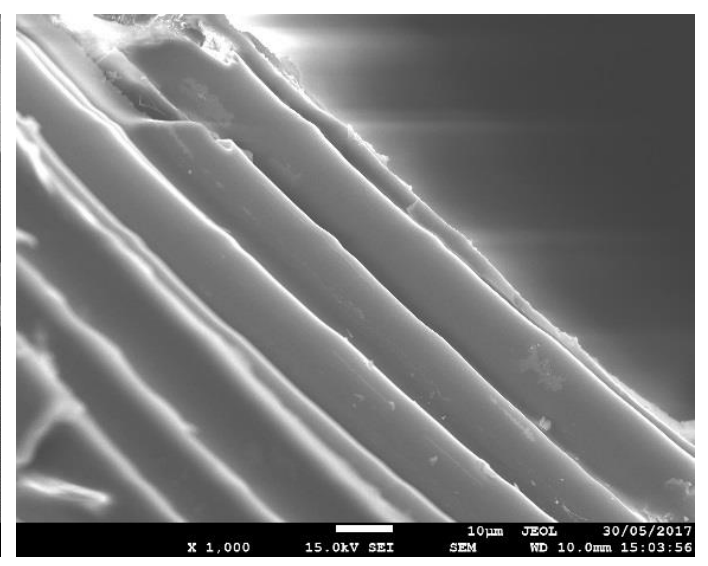

(b)

Figure 8. SEM images of (a) BFRP and (b) GFRP exposed to DW at $60{ }^{\circ} \mathrm{C}$ for 180 days (Adapted from [38], with permission from Elsevier, 2018). 
Fibres and fibre-matrix in CFRP appeared unattacked, clean and smooth after exposure to SWSSNC or NC at $60^{\circ} \mathrm{C}$ for 180 days (Figure 9).

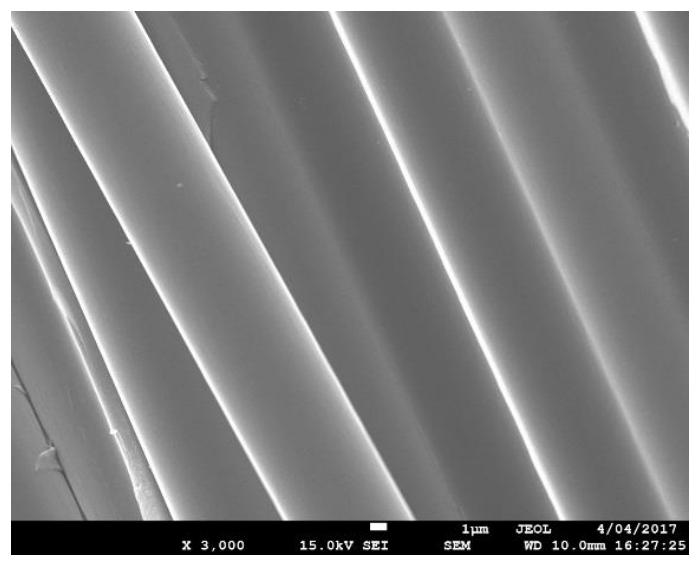

(a)

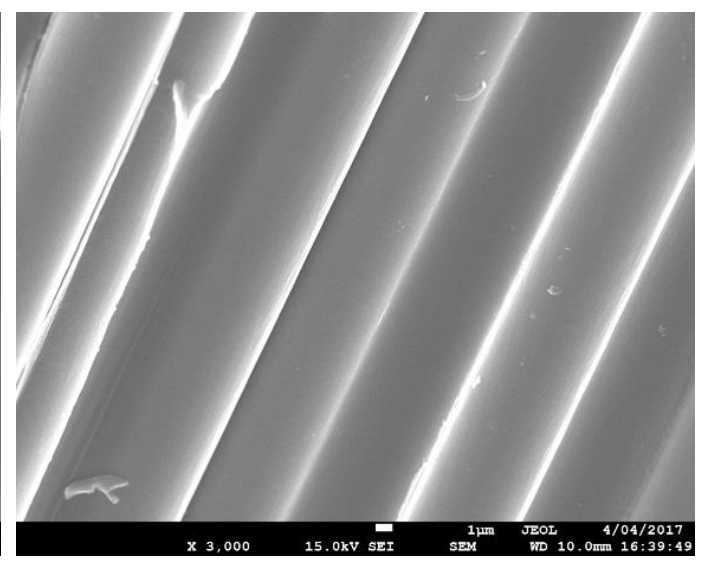

(b)

Figure 9. SEM images for 180-day exposed CFRP and then fractured in liquid N2: (a) SWSSC and (b) NC (Adapted from [38], with permission from Elsevier, 2018).

\section{Conclusions}

Seawater and sea sand concrete (SWSSC) possesses a great potential as an alternative to traditional concrete since it can significantly address the huge problem of use of fresh water and dredging of river sand that are used in huge quantities in production of traditional concrete.

However, material of reinforcement for SWSSC needs to be highly corrosion resistant because the traditional reinforcement of steel will suffer unacceptably high corrosion rate due to very high chloride contents of seawater.

This article discusses the use of fibre-reinforced polymer (FRP) as a suitable alternative reinforcement in SWSSC. The article provides an overview of the reported literature on degradation of different FRP types in normal concrete, and provides a comparison with SWSSC. The degradation of FRPs (described in terms of water uptake) is reported to be considerably different in the normal concrete and chloride-containing alkaline SWSSC environments. More importantly, the article also identifies the gross lack of systematic work to understand the degradation kinetics and mechanisms of FRP in the chloride-containing alkaline SWSSC environment. It is interesting that the seawater-FRP combination has a beneficial effect in resistance of FRP to degradation.

Author Contributions: This review was conceptualized by R.K.S.R. who also undertook the major part of writing, with considerable assistance from F.G. and S.A.-S., X-L.Z. and R.J. contributed to this article with their extensive expertise in composite research.

Funding: The authors wish to acknowledge the financial support provided by the Australian Research Council (ARC) through an ARC Discovery Grant (DP160100739).

Conflicts of Interest: The authors declare no conflict of interest.

\section{References}

1. UN News. UN Projects World Population to Reach 8.5 Billion by 2030, Driven by Growth in Developing Countries. Available online: http:/ / www.un.org/apps/news/story.asp?NewsID=51526\#.WTO4TBOGPjA (accessed on 4 June 2017).

2. ECOSMART. A Concrete Contribution to the Environment-Statistics. Available online: http:// ecosmartconcrete.com/?page_id=208 (accessed on 24 December 2014).

3. JCI. Technical Committee on the Use of Sea Water in Concrete. Available online: http:/ / www.jci-net.or.jp/ $\sim$ tc121a/shushi-E.html (accessed on 24 December 2014). 
4. Singapore's sand shortage-The hourglass effect. The Economist, 8 October 2009. Available online: https: / / www.economist.com/node/14588255/print?story_id=14588255 (accessed on 24 December 2014).

5. Sand shortage hits city engineers. Deccan Chronicle, 8 December 2013. Available online: https://www. deccanchronicle.com/131208/news-current-affairs/article/sand-shortage-hits-city-engineers (accessed on 8 December 2013).

6. Coastal Buildings and Infrastructure: E-Alert November 2009. Available online: https://www.maddocks. com.au/coastal-buildings-and-infrastructure-e-alert-november-2009/ (accessed on 5 January 2015).

7. Davalos, J.F.; Chen, Y.; Ray, I. Long-term durability prediction models for GFRP bars in concrete environment. J. Compos. Mater. 2012, 46, 1899-1914. [CrossRef]

8. Wang, Z.; Huang, X.; Xian, G.; Li, H. Effects of surface treatment of carbon fiber: Tensile property, surface characteristics, and bonding to epoxy. Polym. Compos. 2016, 37, 2921-2932. [CrossRef]

9. Micelli, F.; Nanni, A. Durability of FRP rods for concrete structures. Constr. Build. Mater. 2004, 18, 491-503. [CrossRef]

10. Chen, Y.; Davalos, J.F.; Ray, I.; Kim, H.-Y. Accelerated aging tests for evaluations of durability performance of FRP reinforcing bars for concrete structures. Compos. Struct. 2007, 78, 101-111. [CrossRef]

11. Wu, G.; Dong, Z.-Q.; Wang, X.; Zhu, Y.; Wu, Z.-S. Prediction of long-term performance and durability of BFRP bars under the combined effect of sustained load and corrosive solutions. J. Compos. Constr. 2014, 19, 04014058. [CrossRef]

12. Robert, M.; Benmokrane, B. Combined effects of saline solution and moist concrete on long-term durability of GFRP reinforcing bars. Constr. Build. Mater. 2013, 38, 274-284. [CrossRef]

13. Benmokrane, B.; Wang, P.; Ton-That, T.M.; Rahman, H.; Robert, J.F. Durability of glass fiber-reinforced polymer reinforcing bars in concrete environment. J. Compos. Constr. 2002, 6, 143-153. [CrossRef]

14. Robert, M.; Cousin, P.; Benmokrane, B. Durability of GFRP reinforcing bars embedded in moist concrete. J. Compos. Constr. 2009, 13, 66-73. [CrossRef]

15. Benmokrane, B.; Elgabbas, F.; Ahmed, E.A.; Cousin, P. Characterization and comparative durability study of glass/vinylester, basalt/vinylester, and basalt/epoxy FRP bars. J. Compos. Constr. 2015, 19, 04015008. [CrossRef]

16. Chen, Y.; Davalos, J.F.; Ray, I. Durability prediction for GFRP reinforcing bars using short-term data of accelerated aging tests. J. Compos. Constr. 2006, 10, 279-286. [CrossRef]

17. Dong, Z.; Wu, G.; Xu, Y. Experimental study on the bond durability between steel-FRP composite bars (SFCBs) and sea sand concrete in ocean environment. Constr. Build. Mater. 2016, 115, 277-284. [CrossRef]

18. Kamal, A.; Boulfiza, M. Durability of GFRP rebars in simulated concrete solutions under accelerated aging conditions. J. Compos. Constr. 2010, 15, 473-481. [CrossRef]

19. Nkurunziza, G.; Benmokrane, B.; Debaiky, A.S.; Masmoudi, R. Effect of sustained load and environment on long-term tensile properties of glass fiber-reinforced polymer reinforcing bars. ACI Struct. J. 2005, 102, 615.

20. Karbhari, V.; Chin, J.; Hunston, D.; Benmokrane, B.; Juska, T.; Morgan, R.; Lesko, J.; Sorathia, U.; Reynaud, D. Durability gap analysis for fiber-reinforced polymer composites in civil infrastructure. J. Compos. Constr. 2003, 7, 238-247. [CrossRef]

21. Byars, E.A.; Waldron, P.; Dejke, V.; Demis, S.; Heddadin, S. Durability of FRP in concrete-deterioration mechanisms. Int. J. Mater. Prod. Technol. 2003, 19, 28-39. [CrossRef]

22. Nkurunziza, G.; Debaiky, A.; Cousin, P.; Benmokrane, B. Durability of GFRP bars: A critical review of the literature. Prog. Struct. Eng. Mater. 2005, 7, 194-209. [CrossRef]

23. Ceroni, F.; Cosenza, E.; Gaetano, M.; Pecce, M. Durability issues of FRP rebars in reinforced concrete members. Cem. Concr. Compos. 2006, 28, 857-868. [CrossRef]

24. Serbescu, A.; Guadagnini, M.; Pilakoutas, K. Mechanical characterization of basalt FRP rebars and long-term strength predictive model. J. Compos. Constr. 2014, 19, 04014037. [CrossRef]

25. Wu, G.; Wang, X.; Wu, Z.; Dong, Z.; Xie, Q. Degradation of basalt FRP bars in alkaline environment. Sci. Eng. Compos. Mater. 2015, 22, 649-657. [CrossRef]

26. Wang, Z.; Zhao, X.-L.; Xian, G.; Wu, G.; Singh, R.; Al-Saadi, S.; Haque, A. Long-term durability of basalt-and glass-fibre reinforced polymer (BFRP/GFRP) bars in seawater and sea sand concrete environment. Constr. Build. Mater. 2017, 139, 467-489. [CrossRef]

27. Wang, Z.; Zhao, X.-L.; Xian, G.; Wu, G.; Singh, R.; Al-Saadi, S. Durability study on interlaminar shear behaviour of basalt-, glass-and carbon-fibre reinforced polymer (B/G/CFRP) bars in seawater sea sand concrete environment. Constr. Build. Mater. 2017, 156, 985-1004. [CrossRef] 
28. Li, Y.; Zhao, X.; Singh, R.; Al-Saadi, S. Tests on seawater and sea sand concrete-filled CFRP, BFRP and stainless steel tubular stub columns. Thin-Walled Struct. 2016, 108, 163-184. [CrossRef]

29. Li, Y.; Zhao, X.; Singh, R.; Al-Saadi, S. Experimental study on seawater and sea sand concrete filled GFRP and stainless steel tubular stub columns. Thin-Walled Struct. 2016, 106, 390-406. [CrossRef]

30. Chu, W.; Wu, L.; Karbhari, V.M. Comparative degradation of pultruded E-glass/vinylester in deionized water, alkaline solution, and concrete leachate solution. J. Appl. Polym. Sci. 2006, 99, 1405-1414. [CrossRef]

31. Wu, G.; Wang, X.; Wu, Z.; Dong, Z.; Zhang, G. Durability of basalt fibers and composites in corrosive environments. J. Compos. Mater. 2015, 49, 873-887. [CrossRef]

32. Al-Salloum, Y.A.; El-Gamal, S.; Almusallam, T.H.; Alsayed, S.H.; Aqel, M. Effect of harsh environmental conditions on the tensile properties of GFRP bars. Compos. Part B: Eng. 2013, 45, 835-844. [CrossRef]

33. Kim, H.-Y.; Park, Y.-H.; You, Y.-J.; Moon, C.-K. Short-term durability test for GFRP rods under various environmental conditions. Compos. Struct. 2008, 83, 37-47. [CrossRef]

34. Fiore, V.; Scalici, T.; Di Bella, G.; Valenza, A. A review on basalt fibre and its composites. Compos. Part B Eng. 2015, 74, 74-94. [CrossRef]

35. Wang, Z.; Zhao, X.-L.; Xian, G.; Wu, G.; Singh, R.; Al-Saadi, S. Effect of sustained load and seawater and sea sand concrete environment on durability of basalt- and glass-fibre reinforced polymer (B/GFRP) bars. Corros. Sci. 2018, 138, 200-218. [CrossRef]

36. El-Hassan, H.; El-Maaddawy, T.; Al-Sallamin, A.; Al-Saidy, A. Performance evaluation and microstructural characterization of GFRP bars in seawater-contaminated concrete. Constr. Build. Mater. 2017, 147, 66-78. [CrossRef]

37. Guo, F.; Al-Saadi, S.; Singh, R.; Zhao, X. Durability of Carbon Fiber Reinforced Polymer (Cfrp) With Combined Use Of Seawater Sea Sand Concrete (SWSSC). In Proceedings of the Sixth Asia-Pacific Conference on FRP in Structures (APFIS 2017), Singapore, 19-21 July 2017.

38. Guo, F.; Al-Saadi, S.; Singh, R.; Zhao, X.L. Durability of Fiber Reinforced Polymer (FRP) in Simulated Seawater Sea Sand Concrete (SWSSC) Environment. Corros. Sci. 2018. [CrossRef]

39. Ngono, Y.; Maréchal, Y.; Mermilliod, N. Epoxy-Amine Reticulates Observed by Infrared Spectrometry. I: Hydration Process and Interaction Configurations of Embedded $\mathrm{H}_{2} \mathrm{O}$ Molecules. J. Phys. Chem. B 1999, 103, 4979-4985. [CrossRef]

40. Noobut, W.; Koenig, J. Interfacial behavior of epoxy/E-glass fiber composites under wet-dry cycles by fourier transform infrared microspectroscopy. Polym. Compos. 1999, 20, 38-47. [CrossRef]

41. Smith, R.E.; Larsen, F.N.; Long, C.L. Epoxy resin cure. II. FTIR analysis. J. Appl. Polym. Sci. 1984, 29, 3713-3726. [CrossRef]

42. Socrates, G. Infrared characteristic group frequencies, Tables and charts. J. Am. Chem. Soc. 1995, 117, 1671.

43. Yang, Y.; Xian, G.; Li, H.; Sui, L. Thermal aging of an anhydride-cured epoxy resin. Polym. Degrad. Stab. 2015, 118, 111-119. [CrossRef]

44. Liu, M.Y.; Zhu, H.G.; Siddiqui, N.A.; Leung, C.K.; Kim, J.K. Glass fibers with clay nanocomposite coating: Improved barrier resistance in alkaline environment. Compos. Part. A Appl. Sci. Manuf. 2011, 42, 2051-2059. [CrossRef]

45. Rybin, V.; Utkin, A.; Baklanova, N. Alkali resistance, microstructural and mechanical performance of zirconia-coated basalt fibers. Cem. Concr. Res. 2013, 53, 1-8. [CrossRef]

46. Rybin, V.; Utkin, A.; Baklanova, N. Corrosion of uncoated and oxide-coated basalt fibre in different alkaline media. Corros. Sci. 2016, 102, 503-509. [CrossRef]

47. Scheffler, C.; Förster, T.; Mäder, E.; Heinrich, G.; Hempel, S.; Mechtcherine, V. Aging of alkali-resistant glass and basalt fibers in alkaline solutions: Evaluation of the failure stress by Weibull distribution function. J. Non-Cryst. Solids 2009, 355, 2588-2595. [CrossRef]

48. Jantzen, C.M.; Brown, K.G.; Pickett, J.B. Durable glass for thousands of years. Int. J. Appl. Glass Sci. 2010, 1, 38-62. [CrossRef]

49. Lipatov, Y.V.; Gutnikov, S.; Manylov, M.; Zhukovskaya, E.; Lazoryak, B. High alkali-resistant basalt fiber for reinforcing concrete. Mater. Des. 2015, 73, 60-66. [CrossRef]

(C) 2018 by the authors. Licensee MDPI, Basel, Switzerland. This article is an open access article distributed under the terms and conditions of the Creative Commons Attribution (CC BY) license (http:/ / creativecommons.org/licenses/by/4.0/). 